\title{
Myanmar health services emerging from decades of neglect
}

W hen Tin Mya developed a sore, swollen stomach in November 2012, it took a four-hour boat ride to reach the nearest hospital in remote western Myanmar.

Lamenting the long, slow haul from her home in Sintat Hmaw, one of dozens of islands off Myanmar's Bay of Bengal coastline, Tin Mya was one of the few patients who wasn't at Sittwe Hospital for treatment of injuries stemming from violence associated with religious tensions between Buddhists and minority Muslims. "It is a shame that we don't have any health facilities," she says.

It's not a rare situation, following a half century of military rule in Myanmar, where health services remain massively underfunded, particularly in outlying ethnic minority areas like Rakhine.

But recent political and economic reforms under President Thein Sein, a former army general, suggest the health sector may be about to get a facelift. It certainly needs it. Combined public and private health spending was only US $\$ 17$ per person per year between 2007 and 2011, the lowest in Asia, according to the World Health Organization (WHO), and just a dollar more than Ethiopia and the war-torn Democratic Republic of Congo.

Although Myanmar's health care is free in theory, in reality, residents must absorb about $90 \%$ of treatment costs, according to WHO. Tin Mya says her family has already spent 50000 kyat (US\$59) to treat her for "stomach distension."

Many hope that will change in the aftermath of the military's government decision to end five decades of absolute military rule and relinquish some of its authority to a nominally civilian government that emerged from elections in 2010 .

In the 2011/12 fiscal year, the junta spent just $1.3 \%$, or US\$110 million of its overall budget on health care, and

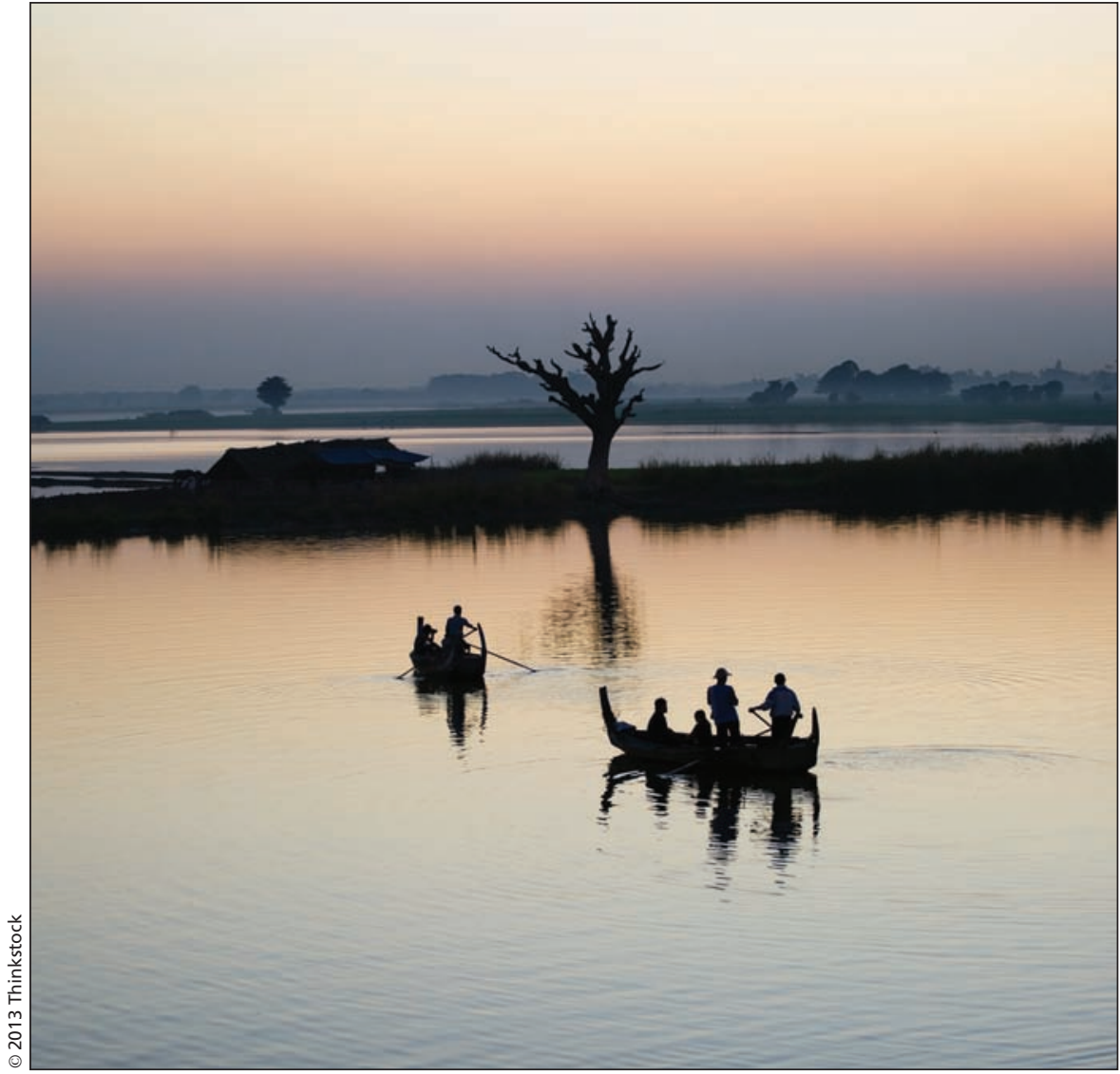

Isolation is major problem in delivering health care in Myanmar, as many people must travel long distances to health facilities.

$23 \%$ on defence. The new government plans to redress that imbalance, by quadrupling health spending in fiscal 2012/13 to more than US\$450 million while reducing defence outlays by one-third.

Dr. Saw Lwin, deputy director-general of the Department of Health, says the extra monies will be used to bolster physician ranks by 1500 , to roughly 8500 . The government is also "increasing the budget for purchasing medicines that can be used at hospitals in rural areas - free of charge for the patients - which can reduce or prevent financial catastrophes due to health."

Health services are also expected to benefit from new social security legislation that requires employers to contribute $6.5 \%$ of salaries to health and welfare costs. In another indicator that the government appears committed to improving health services, it provided US\$5.3 million in November 2012, to administer pentavalent vaccine to 1.4 million children, a first for Myanmar. In support of that, the Global Alliance for Vaccination and Immunisation will contribute US $\$ 10$ million, says spokesman Dan Thomas.

That's a trend many hope will continue as a result of the easing of economic sanctions first implemented in 2003.

The sanctions often made it difficult to export medical and surgical equipment to Myanmar, notes Fenton Holland, general manager of Australian Medical \& Diagnostics. For example, 
the firm's attempts to send radio isotopes for cancer diagnosis and treatment in 2007 were stymied when a home bank stopped processing letters of credit for Myanmar, Holland says. "It got stuck ... [and] took years to clear up the paperwork," along with the payment of customs-issued fines on the order of US\$10 000 apiece.

This dark period for Myanmar also saw the Global Fund withdraw financial aid in 2005 and the French chapter of the international medical relief agency Médecins Sans Frontières pull out entirely in 2006.

But it's hoped the political reforms will expedite the flow of medical equipment, and of foreign aid, the level of which had dropped to just US\$5.20 per person in 2010, as compared with US\$37 and US\$47 per person, in nearby developing countries Cambodia and Laos, according to Organisation for Economic Co-operation and Development data.

Certainly, there are hopeful signs. Global Fund Deputy CEO Dr. Debrework Zewdie led a mission to Myanmar in November 2012 that Yangonbased humanitarian workers believe could sharply increase funding for HIV/AIDS, tuberculosis and malaria treatment. Meanwhile, the United Nations Office for Project Services is expected to provide US $\$ 300$ million for a new fund to treat these three diseases, says Sanjay Mathur, director of the office. "There's a lot of money flowing in now, a lot of positivity."

The question is: Will that cash tide for health reach ethnic border areas such as Rakhine? Mathur would like to think so. But in Sittwe Hospital, one doctor who refused to be named said that despite all the talk of new health monies, he still earns just US\$124 per month, while nurses collect US\$94. In this remote corner of Myanmar, he adds, "nothing changed much in the hospital despite the reforms." - Steve Finch, Yangon, Myanmar, with additional reporting by Swe Win, Sittwe, Myanmar

CMAJ 2013. DOI:10.1503/cmaj.109-4361 